\title{
In vivo manipulation of foreign gene expression by steroid administration in the oviduct of laying hens
}

\author{
H-M Park and T Muramatsu \\ Department of Applied Genetics and Physiology, Graduate School of Bioagricultural Sciences, Nagoya University, Nagoya 464-8601, Japan \\ (Requests for offprints should be addressed to T Muramatsu; Email: tatsuomu@nuagr1.agr.nagoya-u.ac.jp)
}

\begin{abstract}
The experiments described herein were conducted to examine whether or not steroid administration allows in vivo induction of foreign gene expression in the oviduct of laying hens. The chloramphenicol acetyltransferase reporter gene driven by several viral and cellular promoters with or without steroid response elements was transfected by in vivo electroporation. The results indicated that in vivo, as observed in vitro, steroid administration induced transcriptional activities of the promoters with steroid response
\end{abstract}

elements but it did not do so without steroid response elements. Our data implicate, therefore, that in vivo induction of foreign gene expression is possible in the oviduct of laying hens, and that the present in vivo gene transfer approach would serve as a useful tool to elucidate the mechanism of tissue-specific and steroid-induced transcription of chicken egg white genes.

Journal of Endocrinology (1999) 163, 173-179

\section{Introduction}

In the magnum segment of the chicken oviduct, several egg white proteins, including ovalbumin $(\mathrm{Ov})$ and conalbumin, are synthesized and secreted in large amounts under the control of steroid hormones. Therefore, the chicken oviduct is an attractive model to study the mechanism of transcriptional regulation of tissue-specific and steroid-induced gene expression in higher eukaryotes (Sanders \& McKnight 1985).

In the past, most of the studies on the transcriptional mechanism of egg white protein genes such as the $\mathrm{Ov}$ gene have been carried out with cell lines (Muramatsu \& Sanders 1995) or primary cultures of the oviduct cells from estrogen-stimulated immature chicks (Kato et al. 1992, Burbach et al. 1994, Muramatsu \& Sanders 1995). However, no studies have been conducted to elucidate the role of such regulatory elements in oviduct cells of laying hens in which they originally function. There are at least two major reasons for this: (1) the cultured oviduct cells of laying hens were almost completely unresponsive to hormonal stimuli whereas those from immature chicks were responsive (Muramatsu et al. 1995), and (2) DNA transfection in the cultured oviduct cells of laying hens was not possible by popular means such as calcium phosphate precipitation or lipofection.

Recently, it has become possible to transfer DNA in tissues of living animals by various nonviral means such as microparticle bombardment (Yang et al. 1990, Jiao et al. 1993, Muramatsu et al. 1998a), lipofection (Thierry et al. 1995, Muramatsu et al. 1996a) and electroporation (Heller et al. 1996, Muramatsu et al. 1996a,b, Nishi et al. 1996). Of these, in vivo gene electroporation has been more successful than any other nonviral means of transferring DNA into target tissues (Muramatsu et al. 1996a, 1997b). Ochiai et al. (1998) applied this in vivo electroporation technique to transfer the human erythropoietin gene into the oviduct cells of laying hens, and successfully expressed the corresponding recombinant protein albeit in a small amount.

Although nonviral in vivo gene transfer becomes feasible as stated above, it is not yet known whether or not the expression of foreign genes transfected in vivo can be controlled. The present study was conducted, therefore, to examine whether or not the expression of transfected foreign genes could be induced by the administration of steroid hormones when steroid responsive promoters were used.

\section{Materials and Methods}

All animal experiments described here were conducted in accordance with the Guidelines for the Care and Use of Experimental Animals, laid down by the Committee of Experimental Animals Care, Nagoya University, Nagoya, Japan.

\section{Plasmid}

The plasmid, pmiwLuc (Muramatsu et al. 1997b), was made by substituting the firefly luciferase (Luc) gene for 
the bacterial lacZ gene of pmiwZ which was obtained from the Japanese Cancer Research Resources Bank (No. VE052), Osaka, Japan. The plasmid DNAs, pSVCAT and pSVLuc containing the SV40 early promoter (SV), were obtained commercially (Promega, Madison, WI, USA). The transfected reporter plasmid DNAs, pOvCAT100 and pOvCAT900 contained the Ov gene $5^{\prime}$ upstream promoter of two different lengths, i.e. $100 \mathrm{bp}(-87$ to +9$)$ and $900 \mathrm{bp}(-900$ to +9$)$ respectively, fused upstream to the chloramphenicol acetyltransferase (CAT) reporter gene. These two plasmid DNAs were kindly provided by Dr M M Sanders (University of Minnesota, Minneapolis, USA). The CAT reporter plasmid DNAs driven by virus promoter pMMTVCAT containing mouse mammary tumor virus-long terminal repeat (MMTV-LTR) was also kindly provided by Dr M M Sanders. The pRSVCAT containing the Rous sarcoma virus (RSV)-LTR was kindly provided by Dr H Kondou (Osaka University, Osaka, Japan). Both pOvgal100 and pOvLuc100 containing the Ov $100 \mathrm{bp}(-87$ to +9$)$ promoter fused upstream to the bacterial $\beta$-galactosidase gene and firefly luciferase gene respectively, were constructed by substituting these reporter genes for the CAT gene of pOvCAT100.

\section{In vivo gene electroporation}

White Leghorn laying hens (Aichi line) at 18 months of age were used, and lightly anesthetized with diethyl ether. The abdominal cavity was opened surgically, and the magnum portion of the oviduct was exposed. An incision approximately $3 \mathrm{~cm}$ long was made longitudinally in the exposed magnum portion. Into one of the oviduct mucosal folds filled with glandular cells on the mucosa side, $50 \mu \mathrm{l}$ DNA solution containing $20 \mu \mathrm{g}$ pRSVCAT or equal moles of other plasmids were carefully injected together with pOvLuc100 at $5 \mu \mathrm{g}$ to correct for transfection efficiency. After injection, electric square pulses were applied 8 times at $50 \mathrm{~V} / 5 \mathrm{~mm}$ for the loading period of $50 \mathrm{~ms} /$ pulse with an electro-square porator T820 (BTX, San Diego, CA, USA). Pulses were administered to the tissue using a tweezers type electrode. Usually, 4-6 DNA transfers could be carried out in different mucosal folds per bird. After $24 \mathrm{~h}$, the hens were killed and the oviduct portions were removed quickly.

\section{Bioluminescence imaging}

The tissue portion transfected with pSVLuc or pSVCAT was washed with phosphate buffered saline $(137 \mathrm{mM}$ $\mathrm{NaCl}, 2.68 \mathrm{mM} \mathrm{KCl}, 8.08 \mathrm{mM} \mathrm{Na}_{2} \mathrm{HPO}_{4}, \mathrm{pH}$ adjusted to $7 \cdot 0$ ), and transferred to a Petri dish to which $2 \mathrm{ml}$ luciferase substrate buffer (Toyo Ink Co. Ltd, Tokyo, Japan) were added. Bioluminescence was monitored for $10 \mathrm{~min}$.

\section{Cell culture}

Primary cultures of chicken oviduct cells were carried out as described previously (Sanders \& McKnight 1985, 1988). The DNA transfection with calcium phosphate was carried out as described elsewhere (van der Eb \& Graham 1980) immediately after dissociation since the timing of DNA transfection is of crucial importance. In general, the earlier the transfection, the better the steroid induction obtained (Muramatsu et al. 1997a). In combination with the CAT reporter plasmids, the pOvgal100 plasmid was co-transfected at $3.5 \mu \mathrm{g}$ to correct for transfection efficiency. After the transfection, the cells were aliquoted into culture dishes containing the serum-free culture medium and $50 \mathrm{ng} / \mathrm{ml}$ insulin with or without steroid hormones $\left(17 \beta\right.$-estradiol at $2 \times 10^{-7} \mathrm{M}$, and corticosterone at $1 \times 10^{-6} \mathrm{M}$ ), and cultured at $39^{\circ} \mathrm{C}$ for $30 \mathrm{~h}$. The cells were then harvested.

\section{Assays}

The in vitro transfected and cultured oviduct cells were sonicated, and centrifuged at $1000 \times \boldsymbol{g}$ for $10 \mathrm{~min}$. The cell extract was used for measurements of $\beta$-galactosidase and CAT activities. CAT activity was determined as described previously (Sanders \& McKnight 1985, 1988), and the values were expressed as relative CAT activity after the adjustment for $\beta$-galactosidase activity in cultured cells to take account of changes in transfection efficiency. The $\beta$-galactosidase activity was determined fluorometrically as described in the literature (Sambrook et al. 1989). The in vivo transfected oviduct samples were transferred to a $5 \mathrm{ml}$ centrifuge tube to which $10 \mathrm{vol}$ ice-cold buffer A (containing $15 \mathrm{mM}$ Tris, $60 \mathrm{mM} \mathrm{KCl,} 15 \mathrm{mM} \mathrm{NaCl}$, $12 \mathrm{mM}$ EDTA, $1 \mathrm{mM}$ dithiothreitol, $0.15 \mathrm{mM}$ spermine and $0.4 \mathrm{mM}$ phenylmethylsulfonyl fluoride, $\mathrm{pH}$ adjusted to 7.6) (Pothier et al. 1992) were added. After homogenization and sonication, the homogenate was centrifuged at $1000 \times \boldsymbol{g}$ for $10 \mathrm{~min}$. The supernatant was transferred to a new tube, and an aliquot of $20 \mu \mathrm{l}$ was used for the luciferase assay. The remaining cell extract was heated at $70{ }^{\circ} \mathrm{C}$ for $3 \mathrm{~h}$ to inactivate endogenous acetylases, and centrifuged at $1000 \times \boldsymbol{g}$ for $10 \mathrm{~min}$. The resultant supernatant was used for the CAT assay as in the in vitro experiment. The values were expressed as relative CAT activity after the adjustment for luciferase activity to take account of changes in transfection efficiency. The luciferase activity was determined by using a Pica Gene kit (Toyo Ink Co. Ltd) according to the instructions given by the manufacturer.

\section{Statistical analysis}

Usually the same experiments were repeated at least twice, and analysis of variance was carried out on the pooled data (Snedecor \& Cochran 1980). Where necessary, 


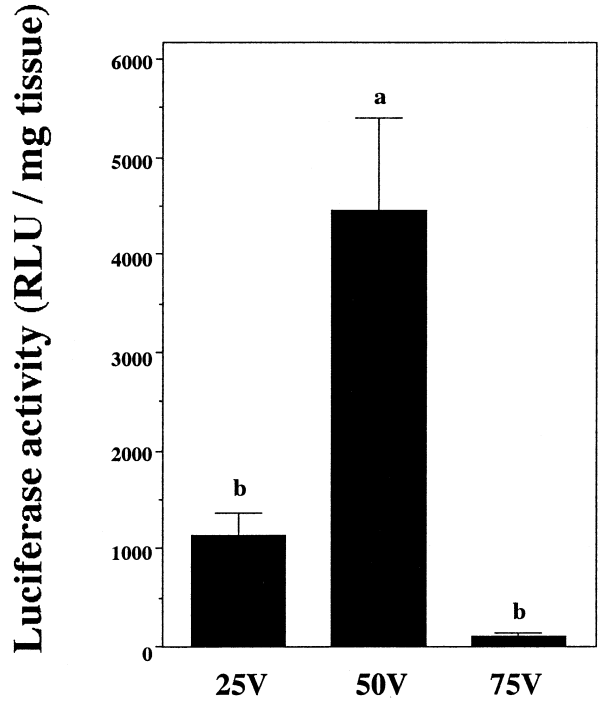

Figure 1 Activity of firefly luciferase expressed in vivo in the oviduct of laying hens. In vivo DNA transfection was carried out by electroporation with $20 \mu \mathrm{g}$ pmiwLuc at different voltages. Luciferase activities were measured $24 \mathrm{~h}$ after the transfection. Results are means \pm S.E.M. of 3 or 4 replicates. RLU, relative light units. ${ }^{\mathrm{a}, \mathrm{b}}$ Means not sharing a common letter are significantly different at $P<0 \cdot 05$.

normalized CAT activities were transformed to their logarithmic values to stabilize error variance prior to the analysis. Significance of differences between means was inspected by Duncan's multiple range test using a commercially available statistical package (SAS 1985).

\section{Results}

Voltage optimization of in vivo gene electroporation

In the first experiment, voltage optimization of in vivo gene electroporation was attempted. The results showed that the value for luciferase gene expression (relative light units/mg tissue) was significantly increased by raising voltages from 25 to $50 \mathrm{~V}$, and decreased substantially from 50 to $75 \mathrm{~V}$ (Fig. 1). Therefore, the optimal voltage was considered to be $50 \mathrm{~V}$ under the present experimental conditions, and this voltage was used throughout the subsequent in vivo experiments.

\section{Bioluminescence imaging}

In the following experiment, $10 \mu \mathrm{g}$ pSVLuc or pSVCAT were similarly transfected by in vivo gene electroporation in the oviduct of laying hens. Twenty-four hours after the transfection, bioluminescence imaging was carried out by using the single photon imaging system (Argus-50/2D, Hamamatsu Photonics, Hamamatsu, Japan). The result of photon imaging is shown in Fig. 2. Significant bioluminescence, the intensity of which is shown in the right column ranging from red (strong) to dark blue (weak), was

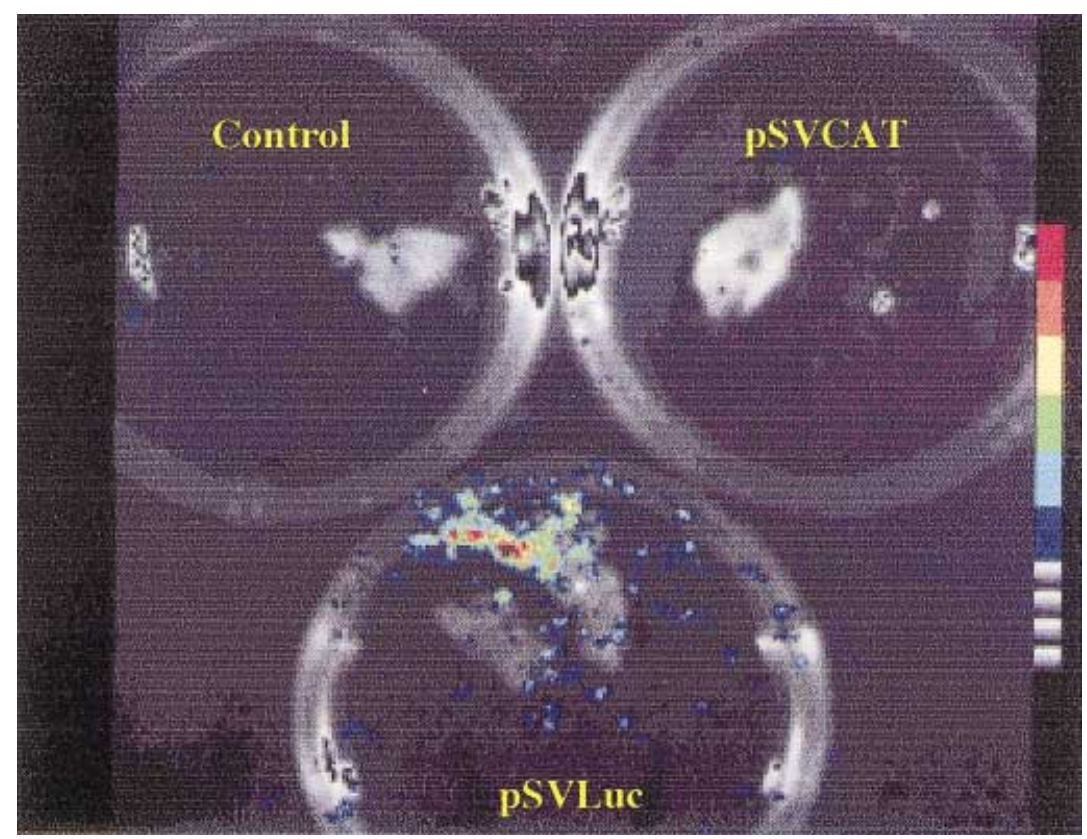

Figure 2 Bioluminescence imaging of the chicken oviduct. Either pSVLuc or pSVCAT was transfected in vivo in the chicken oviduct by electroporation at $10 \mu \mathrm{g}$. Intensity of bioluminescence detected by the single photon imaging system was indicated by the right column ranging from red (strong) to dark blue (weak). 
observed only in the tissue portion transfected with the Luc reporter gene (pSVLuc), but not with CAT (pSVCAT) or the (Control) reporter gene.

Induction of transcriptional activity in the oviduct of laying hens in vivo by steroid treatment

To examine whether or not steroid administration induces transcription of foreign genes driven by viral and cellular promoters with or without steroid response elements, steroid hormones were injected subcutaneously around the neck for 3 consecutive days. The amounts of each steroid hormone were chosen to give equivalent (in total of $1.4 \times 10^{-4} \mathrm{~mol}$ corticosterone; experiment 3 ), $\times 1$ (in total of $2.7 \times 10^{-5} \mathrm{~mol} 17 \beta$-estradiol and $1.4 \times 10^{-4} \mathrm{~mol}$ corticosterone; experiment 4$)$ or $\times 10(10$-fold $)$ concentrations (experiment 4) of those added to the culture medium in the in vitro study, provided that the injected steroids were evenly distributed within the body of a $1 \cdot 7-\mathrm{kg}$ laying hen. Subsequently, the three viral promoters, i.e. SV, MMTV-LTR and RSV-LTR were transfected in vivo into the oviduct of laying hens (experiment 3 ), and the two viral promoters, i.e. SV and MMTVLTR, and two cellular promoters, Ov100 and Ov900, were transfected in vivo likewise (experiment 4 ).

The values for relative CAT activity and fold induction by the corticosterone administration in experiment 3 are shown in Fig. 3 (panels A and B). In both the SV and RSV-LTR promoters, no in vivo induction in CAT values was found in the presence of corticosterone, whereas a substantial in vivo induction was detected in the MMTVLTR promoter in the presence of this hormone.

The values for relative CAT activity in experiment 4 are given in Fig. 4 (panel A). The transcriptional activities of MMTV-LTR and Ov900 were significantly increased as reported in the in vitro experiment with steroid hormones (Ringold 1983, Otten et al. 1988, Haecker et al. 1995), although the extent of steroid induction in the MMTV-LTR and Ov900 appeared to be slightly weaker in experiment 4 than in experiment 3 , approximately four to five times at the 10-fold concentration (Fig. 4, panel B). As was expected, no steroid induction was detected in vivo in the SV and Ov100 promoters.

Transcriptional activity in the in vitro oviduct cell culture system

Finally, to confirm the steroid induction of transcriptional activity of these viral and cellular promoters in vitro, the plasmid, pSVCAT, pMMTVCAT, pOvCAT100 or pOvCAT900 was transfected in primary cultures of oviduct cells from steroid-stimulated immature chicks by calcium phosphate precipitation. The results are shown in Fig. 5, panel A, indicating that the MMTV-LTR which contains a glucocorticoid receptor binding site (von der Ahe et al. 1985) showed an increased transcriptional
A

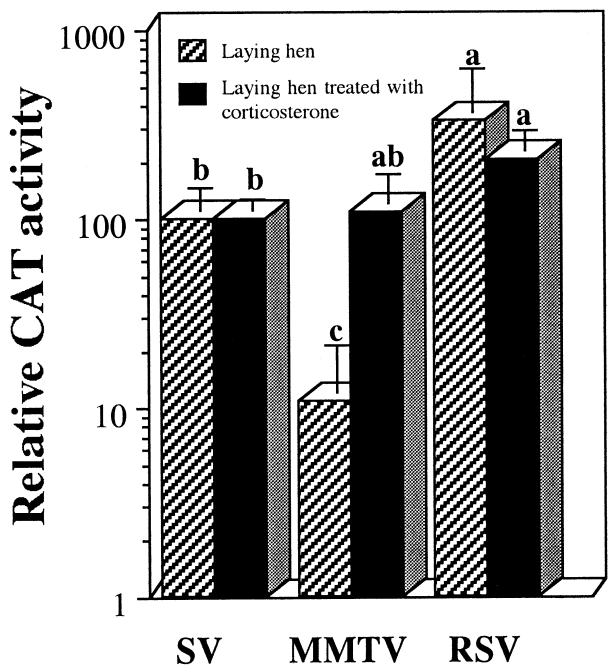

$\mathbf{B}$

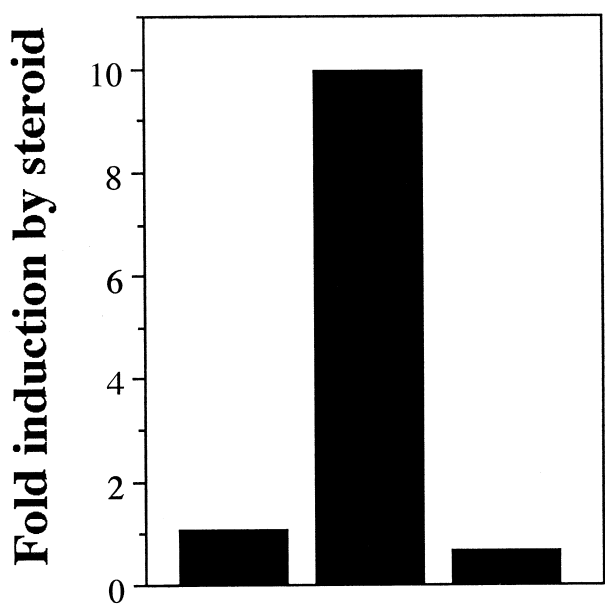

SV MMTV RSV

Figure 3 Activity of CAT driven by viral promoters together with the extent of steroid induction in the oviduct of laying hens injected with corticosterone at $1.4 \times 10^{-4}$ mol. (A) In vivo DNA transfection was carried out by electroporation with pSVCAT (SV), pMMTVCAT (MMTV) or pRSVCAT (RSV) at a dose of $20 \mu \mathrm{g}$ (pRSVCAT) or equal moles of other plasmids. In all samples, $5 \mu \mathrm{g}$ pOvLuc100 were co-transfected as an internal control to normalize transfection efficiency. Relative CAT activity was measured $24 \mathrm{~h}$ after the transfection. Results are means \pm S.E.M. of 4 replicates. ${ }^{a, b, c}$ Any two means not sharing a common letter are significantly different at $P<0 \cdot 05$. (B) The extent of steroid induction was calculated from relative CAT values with steroid hormones divided by the corresponding ones without steroid hormones, and shown in terms of fold induction.

activity in the presence of corticosterone. The extent of induction is illustrated more clearly in Fig. 5, panel B. The Ov100 and Ov900 promoters had roughly the same levels of relative CAT activity with steroid hormones. However, 
without steroid hormones, transcriptional activity of the Ov900 promoter was remarkably attenuated. Thus, as reported previously (Sanders \& McKnight 1985, Haecker et al. 1995), steroid-induced gene expression was confirmed in the oviduct cells from steroid-stimulated immature chicks cultured in vitro, and the induction responses were analogous to those found in vivo in the oviduct of living layers.

\section{Discussion}

The experiments described herein suggest that steroid hormone administration induces foreign gene expression in vivo in the oviduct of laying hens when steroid responsive promoters are used (Figs 3 and 4). The extent of induction in the oviduct in vivo was found to be roughly the same as that in the oviduct cells cultured in vitro

\section{A}
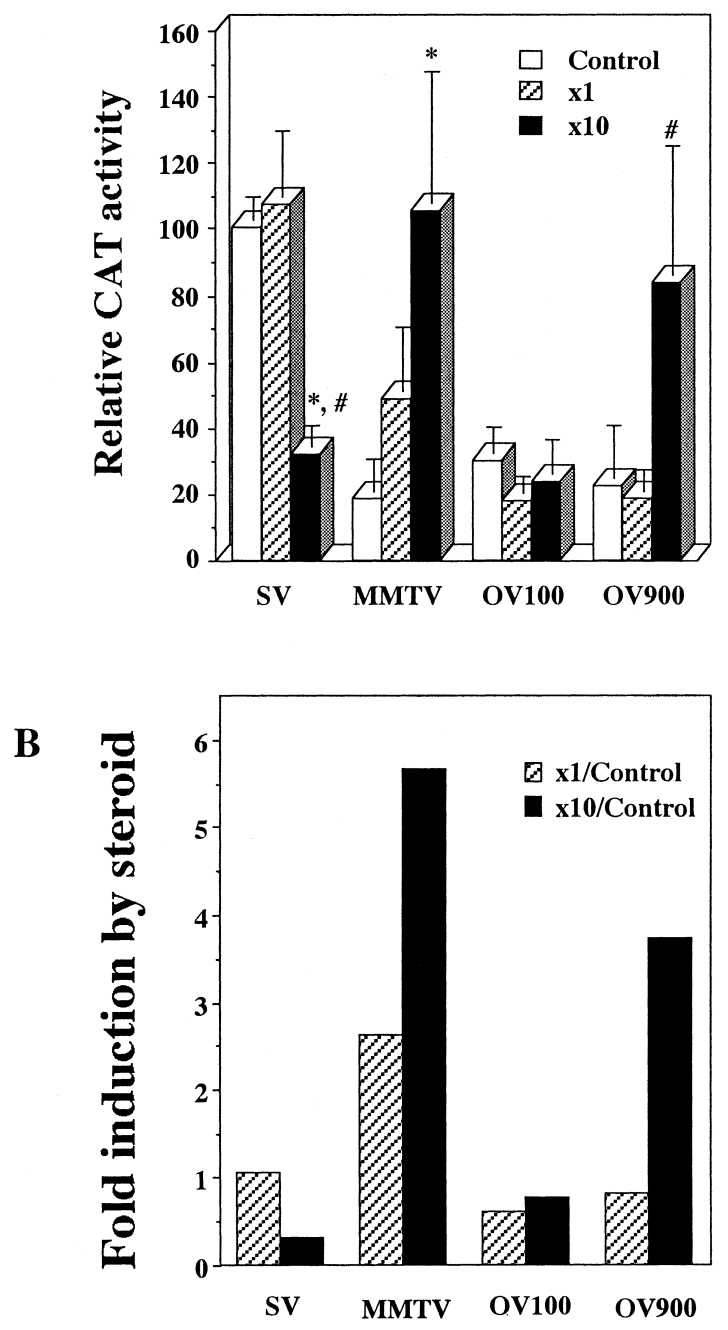

(Fig. 5). For in vivo manipulation of gene expression in the present study, the MMTV-LTR and corticosterone were employed for the promoter and steroid hormone respectively in experiment 3 , as the glucocorticoid-stimulated transcription through multiple glucocorticoid receptor binding sites in the MMTV-LTR has been well known (Ringold 1983, Otten et al. 1988). The Ov100 and Ov900 promoters were also employed in addition to the MMTVLTR in experiment 4 because Ov900 contains negative regulatory element and steroid dependent response element in the $5^{\prime}$-flanking region which are known to confer responsiveness to steroidal stimuli (Haecker et al. 1995), but Ov100 does not have these coordinated steroid response elements.

The basal gene expression level conferred by the MMTV promoter in the absence of exogenous corticosterone was lower than those conferred by the SV40 and RSV promoters (Figs 3 and 4). Although this particular viral promoter retains some steroid inducible activity in vivo in the oviduct of laying hens, there may not be sufficient transcription factors to interact with the glucocorticoid response elements and other regulatory elements in oviduct glandular cells. In the absence of steroid hormones, the cellular promoters, i.e. Ov100 and especially Ov900, showed weaker transcriptional activity than did the SV40 promoter. However, this is not surprising since in an episomal form which would account for most transfected genes by the in vivo electroporation technique, gene transcriptional activity as high as that of endogenous levels is not always attained. Lack of some important factors associated with integrated genes such as higher order structure of DNA, or elements like locus control region and matrix attachment elements (Muramatsu \& Sanders 1995) might be responsible for the poor foreign gene expression.

In vivo gene transfer by utilizing electroporation in the present study can be conducted relatively simply and
Figure 4 Activity of CAT driven by viral promoters together with the extent of steroid induction in the oviduct of laying hens injected with steroid hormones. Steroid hormones at two concentrations, i.e. $\times 1$ (in total of $2 \cdot 7 \times 10^{-5} \mathrm{~mol} 17 \beta$-estradiol and $1.4 \times 10^{-4} \mathrm{~mol}$ corticosterone $)$ and $\times 10(10$ times the $\times 1$ concentration) were injected subcutaneously for 3 consecutive days. On the last day of steroid injection, CAT reporter plasmids were transfected in vivo in the oviduct. (A) In vivo DNA transfection was carried out by electroporation with pSVCAT (SV), pMMTVCAT (MMTV), pOvCAT100 (OV100) or pOvCAT900 (OV900) at a dose of $20 \mu \mathrm{g}$ PMMTVCAT or equal moles of other plasmids. In all transfection samples, $5 \mu \mathrm{g}$ pOvLuc100 were co-transfected as an internal control to normalize transfection efficiency. CAT activities were measured $24 \mathrm{~h}$ after the transfection. Results are means \pm S.E.M. of 4 replicates. (B) To calculate the extent of steroid induction, CAT values with steroid hormones were divided by those without steroid hormones, and shown in terms of fold induction. ${ }^{*} P<0 \cdot 05$ compared with the corresponding no steroid control. $\# P<0 \cdot 05$ compared with the corresponding $\times 1$-treated group. 
A

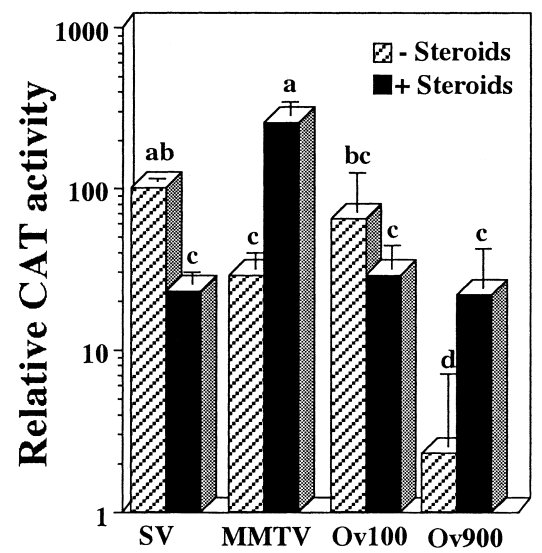

B

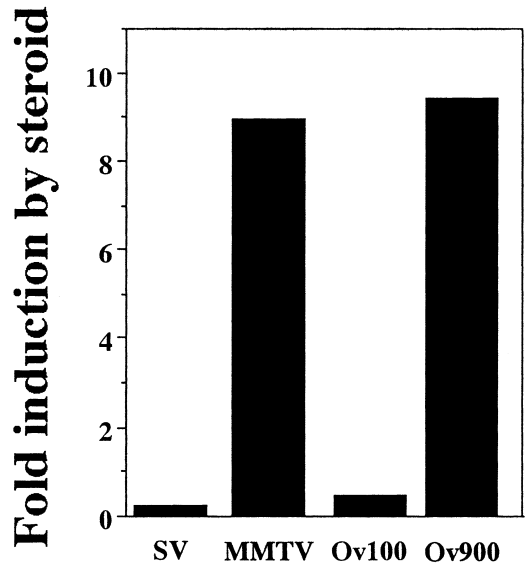

Figure 5 Activity of CAT together with the extent of steroid induction in primary cultures of oviduct cells from steroidstimulated immature chicks. (A) In vitro transfection was carried out by calcium phosphate precipitation with pSVCAT (SV), pMMTVCAT (MMTV), pOvCAT100 (Ov100) or pOvCAT900 (Ov900) at a dose of $20 \mu \mathrm{g}$ pMMTVCAT per dish or equal moles of other plasmids. The cells were cultured with $(+)$ or without $(-)$ steroid hormones, i.e. $17 \beta$-estradiol and corticosterone at $2 \times 10^{-7} \mathrm{M}$ and $1 \times 10^{-6} \mathrm{M}$ respectively for $30 \mathrm{~h}$. In all transfection samples, $3 \cdot 5 \mu \mathrm{g}$ pOvgal 100 were co-transfected as an internal control to normalize transfection efficiency. Results are means \pm S.E.M. of 5 or 6 replicates. (B) To calculate the extent of steroid induction, CAT values with steroid hormones were divided by those without steroid hormones, and shown in terms of fold induction. ${ }^{\mathrm{a}, \mathrm{b}, \mathrm{c}, \mathrm{d}}$ Any two means not sharing a common letter are significantly different at $P<0 \cdot 05$.

quickly. For one bird, the entire procedure is completed within an hour including operation. The efficiency of gene transfection in the oviduct in vivo is generally higher than that in the oviduct cell cultures in vitro. By utilizing a bacterial $\beta$-galactosidase expressing plasmid construct, the heterologous oviduct cell population expressing the transgene ranged from approximately 20 to $30 \%$ of the total cells mainly consisting of glandular cells in a transfected area of mucosal folds (H-M Park \& $\mathrm{T}$ Muramatsu, unpublished results). Good transfection efficiency in the in vivo gene electroporation system was also substantiated by the fact that the detectable amount of human erythropoietin protein was produced in vivo but not in the cultured oviduct cells in vitro (Ochiai et al. 1998). The data in the mouse testis further support a better gene transfer efficiency by gene electroporation in the in vivo system than in in vitro cultures (Muramatsu et al. 1996c).

In addition to controllable gene expression, tissue- or cell-specific foreign gene expression is attainable by in vivo gene electroporation as shown in the mouse testis (Muramatsu et al. 1997b). This would be of particular importance if one wishes to express foreign genes only in specific cells in a specific tissue. For example, by comparing the pattern of foreign gene expression in different cells and tissues including the oviduct, one might even be able to identify tissue-specific elements in the Ov gene promoter region. Such inter-tissue comparisons cannot be easily done in the in vitro primary culture system as the establishment of optimal culture conditions requires timeconsuming work, whereas in the in vivo circumstances tissues are a priori in the best 'culture' condition. This is perhaps one of the most useful applications of in vivo gene electroporation in studying the Ov gene transcriptional regulation.

For in vivo gene electroporation, optimization is an essential step as previous studies suggested that the highest gene expression was obtained at different voltages, number of electric pulses, and loading periods depending on target tissues and animals of interest (Muramatsu et al. 1998b). In the present study, only the voltage was varied (Fig. 1) since it was empirically known that the longer period of $50 \mathrm{~ms}$ with 8 pulses would cause serious irreversible tissue damage.

In the in vitro cell culture system with steroid hormones in the present study and the work of others (Sanders \& McKnight 1985), the concentrations of supplemented estradiol and corticosterone used were about 1000-fold higher than physiological levels (Freeman 1984, Wells \& Gilbert 1984). The in vivo experiments showed that a pharmacological concentration equivalent to or 10 times higher than the in vitro culture levels was required to cause the induction of transcriptional activities of MMTV-LTR and Ov900 promoters. This suprapharmacological dose of exogenous steroid hormones would disrupt normal ovulation and oviposition cycles in laying hens, suggesting that the induced gene expression may not necessarily reflect endogenous regulation.

The reason for the apparently higher dose needed in vivo remains unknown. It may possibly be due to the delay of hormone delivery from the injection site to the oviduct in vivo. Alternatively, because of universal gene transfer into the entire oviduct cell population in vivo, the proportion of steroid responsive cells, i.e. glandular cells, into which foreign genes were transfected may be low. This 
would, in turn, result in suprapharmacological doses being required for the induction of gene expression in vivo. Moreover, in the in vivo situation there are endogenous steroid hormones in plasma so that oviduct glandular cells are already in an induced state with respect to steroid responsive gene promoters. In order to induce gene transcription to a further substantial extent, such high levels may be needed.

\section{Acknowledgements}

We would like to thank Dr M M Sanders for providing the pOvCAT, pConCAT and pMMTVCAT constructs, and Dr H Kondou for the RSV-LTR construct. This research was supported by Grant-in-Aid (No. 0588), Research Fellowships of the Japan Society for the Promotion of Science for Young Scientists.

\section{References}

von der Ahe D, Janich S, Scheidereit C, Renkawitz R, Schütz G \& Beato M 1985 Glucocorticoid and progesterone receptors bind to the same sites in two hormonally regulated promoters. Nature $\mathbf{3 1 3}$ 706-709.

Burbach JPH, Silva SLD, Cox JJ, Adan RAH, Cooney AJ, Tsai M-J \& Tsai SY 1994 Repression of estrogen-dependent stimulation of the oxytocin gene by chicken ovalbumin upstream promoter transcription factor I. Journal of Biological Chemistry 269 15046-15053.

van der Eb A \& Graham F 1980 Assay of transforming activity of tumor virus DNA. Methods in Enzymology 65 826-839.

Freeman BM 1984 Biochemical and physiological data. In Physiology and Biochemistry of the Domestic Fowl, vol 5, pp 407-424. Ed BM Freeman. UK: Academic Press.

Haecker SAE, Muramatsu T, Sensenbaugh KR \& Sanders MM 1995 Repression of the ovalbumin gene involves multiple negative elements including a ubiquitous transcriptional silencer. Molecular Endocrinology 9 1113-1126.

Heller R, Jaroszeski M, Atkin A, Moradpour D, Gilbert R, Wands J \& Nicolau C 1996 In vivo gene electroinjection and expression in rat liver. FEBS Letters 389 225-228.

Jiao S, Cheng L, Wolff JA \& Yang N-S 1993 Particle bombardmentmediated gene transfer and expression in rat brain tissues. Bio/Technology 11 497-502.

Kato S, Tora L, Yamauchi J, Masushige S, Bellard M \& Chambon P 1992 A far upstream estrogen response element of the ovalbumin gene contains several half-palindromic $5^{\prime}$-TGACC-3' motifs acting synergistically. Cell 68 731-742.

Muramatsu T \& Sanders MM 1995 Regulation of ovalbumin gene expression. Poultry and Avian Biology Reviews 6 107-123.

Muramatsu T, Hiramatsu H \& Okumura J 1995 Induction of ovalbumin mRNA by ascorbic acid in primary cultures of tubular gland cells of the chicken oviduct. Comparative Biochemistry and Physiology 112B 209-216.

Muramatsu T, Mizutani Y \& Okumura J 1996a Effects of incubation time and injection sites on gene transfection efficiency in chicken embryos by in ovo lipofection. Animal Science and Technology 67 882-885.

Muramatsu T, Mizutani Y \& Okumura J 1996b Live detection of the firefly luciferase gene expression by bioluminescence in incubating chicken embryos. Animal Science and Technology 67 906-909.
Muramatsu T, Shibata O, Ohmori Y \& Okumura J 1996c In vivo electroporation: a convenient method for gene transfer to testicular cells in mice. Animal Science and Technology 67 975-982.

Muramatsu T, Hiramatsu H, Park H-M, Okumura J, Kawashima M \& Miyoshi S 1997a Estrogen receptor is not primarily responsible for altered responsiveness of ovalbumin mRNA induction in the oviduct from genetically selected high- and low-albumin chicken lines. Comparative Biochemistry and Physiology 116B 391-396.

Muramatsu T, Shibata O, Ryoki S, Ohmori Y \& Okumura J 1997 b Foreign gene expression in the mouse testis by localized in vivo gene transfer. Biochemical and Biophysical Research Communications 233 45-49.

Muramatsu T, Imai T, Park H-M, Watanabe H, Nakamura A \& Okumura J 1998a Gene gun-mediated in vivo analysis of tissuespecific repression of gene transcription driven by the chicken ovalbumin promoter in the liver and oviduct of laying hens. Molecular and Cellular Biochemistry 185 27-32.

Muramatsu T, Nakamura A \& Park H-M 1998 b In vivo electroporation: a powerful and convenient means of nonviral gene transfer to tissues of living animals. International Journal of Molecular Medicine 1 55-62.

Nishi T, Yoshizato K, Yamashiro S, Takeshima H, Sato K, Hamada K, Kuratsu J \& Ushio Y 1996 High-efficiency in vivo gene transfer using intraarterial plasmid DNA injection following in vivo electroporation. Cancer Research 56 1050-1055.

Ochiai H, Park H-M, Nakamura A, Sasaki R, Okumura J \& Muramatsu T 1998 Synthesis of human erythropoietin in vivo in the oviduct of laying hens by localized in vivo gene transfer using electroporation. Poultry Science 77 299-302.

Otten AD, Sanders MM \& McKnight GS 1988 The MMTV LTR promoter is induced by progesterone and dihydrotestosterone but not by estrogen. Molecular Endocrinology 2 143-147.

Pothier F, Ouellet M, Julien J-P \& Guérin SL 1992 An improved CAT assay for promoter analysis in either transgenic mice or tissue culture cells. DNA and Cell Biology 11 83-90.

Ringold GM 1983 Regulation of mouse mammary tumor virus gene expression by glucocorticoid hormones. Current Topics in Microbiology and Immunology 106 79-103.

Sambrook J, Fritsch EF \& Maniatis T 1989 A laboratory manual. In Molecular Cloning, vol 3, pp 16.66-16.67. New York: Cold Spring Harbor Laboratory Press.

Sanders MM \& McKnight GS 1985 Chicken egg white genes: multihormonal regulation in a primary cell culture system. Endocrinology 116 398-405.

Sanders MM \& McKnight GS 1988 Positive and negative regulatory elements control the steroid-responsive ovalbumin promoter. Biochemistry 27 6550-6557.

SAS 1985 SAS User's Guide: Statistics. Version 5. North Carolina: SAS Institute.

Snedecor GW \& Cochran WG 1980 Statistical Methods, edn 7. Iowa: Iowa State University Press.

Thierry AR, Lunardi-Iskandar Y, Bryant JL, Rabinovich P, Gallo RC \& Mahan LC 1995 Systemic gene therapy: biodistribution and long-term expression of a transgene in mice. Proceedings of the National Academy of Sciences of the USA 92 9742-9746.

Wells JW \& Gilbert AB 1984 Steroid hormone production by the ovary. In Physiology and Biochemistry of the Domestic Fowl, vol 5, pp 323-341. Ed BM Freeman. UK: Academic Press.

Yang NS, Burkholder J, Roberts B, Martinell B \& McCabe D 1990 In vivo and in vitro gene transfer to mammalian somatic cells by particle bombardment. Proceedings of the National Academy of Sciences of the USA 87 9568-9572.

Received 19 October 1998

Revised manuscript received 4 May 1999 Accepted 14 June 1999 